\title{
Balancing performance of epoxidized soybean oil (ESO)/poly(lactic acid) composites: Synergistic effects of carbon nanotubes and tannic acid-induced crosslinking of ESO
}

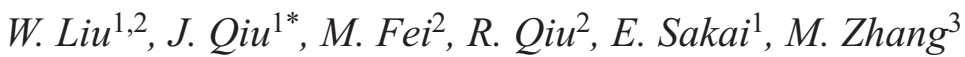 \\ ${ }^{1}$ Department of Machine Intelligence and Systems Engineering, Faculty of Systems Engineering, Akita Prefectural \\ University, 015-0055 Akita, Japan \\ ${ }^{2}$ College of Transportation and Civil Engineering, Fujian Agriculture and Forestry University, 350108 Fuzhou, P. R. China \\ ${ }^{3}$ Key Laboratory of Auxiliary Chemistry \& Technology for Chemical Industry, Ministry of Education, Shaanxi University \\ of Science \& Technology, 710021 Xi'an, China
}

Received 3 July 2018; accepted in revised form 3 September 2018

\begin{abstract}
Highly tough and biobased epoxidized soybean oil (ESO)/poly(lactic acid) (PLA) blends were formulated through in-situ formation of tannic acid-crosslinked ESO (TA-c-ESO) oligomer as a dispersed phase with PLA matrix by dynamic vulcanization technique. To repair the sacrificial strength of the blends and endow the composites with electrical conductivity, different concentrations of CNTs, i.e., 0.5 to $10 \mathrm{wt} \%$, were incorporated into the TA-c-ESO/PLA blends to prepare CNT/TAc-ESO/PLA nanocomposites. The added CNTs selectively localized within the PLA matrix, leading to a reduced size of TAc-ESO phase. The synergistic effects of CNTs and TA-c-ESO phase on the tensile properties, thermal stabilities, crystallization characteristics, and electrical properties of the nanocomposites were fully investigated along with the understanding of CNT reinforcing and TA-c-ESO toughening mechanism. The formation of TA-c-ESO phase significantly increased the fracture elongation and tensile toughness of the blends, while the incorporation of CNTs resulted in increased tensile strength, tensile modulus, and storage modulus of the nanocomposites; the combination of this two effects contributed to the obtained ternary composites with balanced mechanical properties and favorable electrical conductivity.
\end{abstract}

Keywords: polymer composites, mechanical properties, reinforcements, toughening mechanism

\section{Introduction}

Recently, biodegradable and biobased polymers were extensively used to replace nonrenewable and petroleum-based analogues to reduce plastics waste pollution. Poly(lactic acid) (PLA) is a biobased polyester that is originated from starch-rich products including corn and wheat via a fermentation process [1]. PLA possesses attractive properties such as high strength and modulus, easy processability, and biodegradability. Many studies have enabled the production of PLA products with a large-scale level and their various applications in packaging, medicines, textiles, automobiles, etc. [2-4]. However, the intrinsic brittleness of PLA is the main bottleneck that inhibits its wider application.

Blending with other monomers or polymers is easily processed and effective in toughening PLA. Vegetable oils and their derivatives including epoxidized soybean oil (ESO) are attractive materials in blending with PLA due to their flexible molecular chains [5-11]. However, the toughening efficiency is prevented by the immiscibility of these derivatives with PLA. The interfacial compatibility between soybean oil-based derivatives and PLA was greatly increased

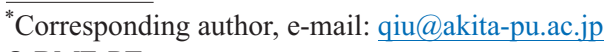

C BME-PT 
by using a soybean oil-PLA star polymer as compatibilizer, which contributed to significantly increased fracture elongation and tensile toughness of soybean oil/PLA blends [12]. A poly(isoprene-b-L-lactide) block copolymer was also used to improve the tensile toughness of polymerized soybean oil/PLA blends [13]. It is reported that dynamic vulcanization is a reactive process that increases the compatibility of each components in PLA-based blends during meltcompounding [14]. The polymerization of ESO was initiated with a cationic initiator during the blending of ESO with PLA to produce fully biobased ESO/PLA blends with high toughness [15]. A sustainable sebacic acid-cured ESO phase was introduced into PLA matrix to increase the toughening efficiency of ESO on PLA blends [16]. Similar work was done on PLA matrix incorporated with diisocyanate-crosslinked castor oil phase $[17,18]$. In our previous work, tannic acid (TA) was used as a green crosslinker for ESO during the dynamic vulcanization of PLA with ESO to generate highly tough TA-c-ESO/PLA blends [19]. As proposed in Figure 1, the possible reactions in the TA-c-ESO/PLA blends include 1) the phenolic -OH groups from TA with the epoxy rings from ESO (Reaction I), 2) the formed-OH groups from Reaction I with other ESO epoxides (Reaction II), 3) the terminal $-\mathrm{COOH}$ groups from PLA with the $-\mathrm{OH}$ groups from TA (Reaction III), and 4) the $-\mathrm{COOH} /$ $-\mathrm{OH}$ groups of PLA with the epoxy rings of ESO (Reaction IV) [20]. These reactions resulted in a stable TA-crosslinked-ESO elastomer formed within
PLA matrix as a dispersed phase and an increased interfacial bonding between the TA-c-ESO phase and PLA, which significantly increased the fracture elongation and tensile toughness of the PLA blends, while the tensile strength and modulus were dramatically reduced.

Nanofillers, such as cellulose nanocrystals [21, 22], graphene [23], montmorillonite [24], $\mathrm{TiO}_{2}$ nanoparticles [25], halloysite nanotubes [26], and carbon nanotubes (CNTs) [27], have been incorporated into the PLA matrix for the preparation of PLA-based nanocomposites with significantly improved mechanical strength. CNT/PLA nanocomposites are particularly attractive due to the ability of CNTs to induce good mechanical strength and stiffness as well as superior thermal and electrical properties [28]. Our previous study found that the PLA nanocomposite with $3 \mathrm{wt} \%$ CNTs obtained from twin-screw extrusion achieved significantly improved tensile strength and modulus as well as electrical conductivity [29]. The key challenges for preparing CNT/PLA nanocomposites are the poor dispersion of CNTs in PLA matrix and filler-matrix interfacial adhesion, which could be alleviated by functionalization of CNTs [30]. However, incorporation of CNTs dramatically deteriorated the impact strength and fracture elongation of the resulting PLA nanocomposites.

Investigations on the toughening of CNT/PLA nanocomposites have been addressed by blending with plasticizers, elastomers, and other flexible polymers. For example, novel electroactive shape memory
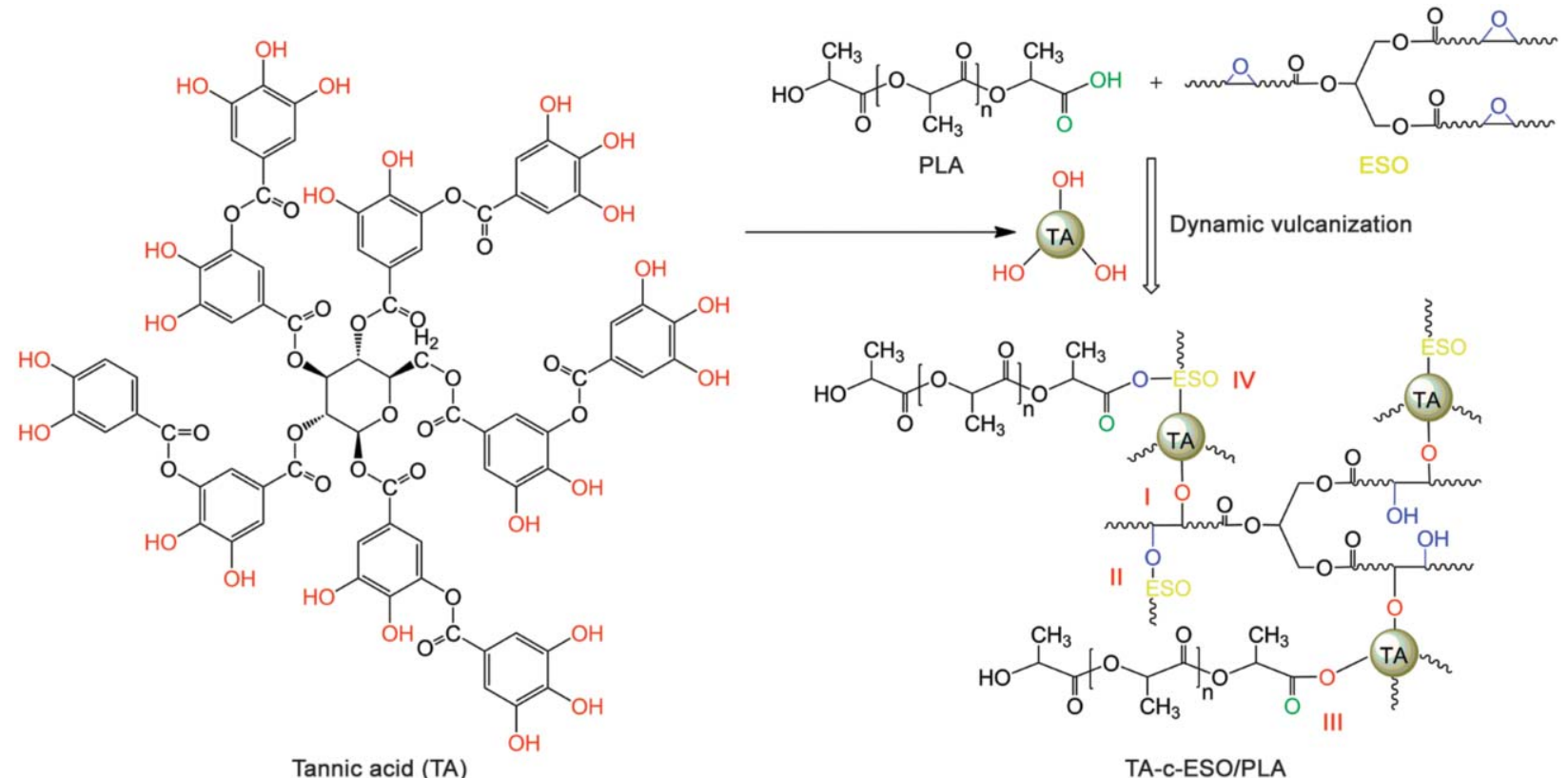

Figure 1. Proposed reactions among TA, ESO and PLA during dynamic vulcanization. 
polymer nanocomposites were prepared from CNTs and ESO or epoxidized linseed oil plasticized PLA [31, 32]. More importantly, the addition of CNTs into an immiscible polymer blends is effective in improving the fracture toughness of the blends, and the toughening efficiency depends on the selective distribution of CNTs in the blend components [33]. The toughness of PLA blends was greatly improved by incorporation of pristine and functionalized CNTs, along with the addition of different toughening phases, such as thermoplastic polyurethane (TPU) [34, 35], polycarbonate $(\mathrm{PC})[36,37]$, poly(butyleneadipate-co-terephthalate) [38], poly(3-hydroxybutyrateco-4-hydroxybutyrate) [39], polystyrene [40], poly (ethylene-co-vinyl acetate) [41, 42], and natural rubber [43]. The mechanical properties and miscibility of PC/PLA blends were greatly increased by simultaneous addition of a compatibilizer and CNTs [44]. Highly conductive PLA/TPU/CNTs nanocomposites with a low percolation threshold and excellent stiffness-toughness balance were obtained via inducing the formation of co-continuous structure in the PLA/ TPU blend matrix [45].

To further develop ESO/PLA-based nanocomposites with superior strength-toughness balance, TA and CNTs were simultaneously incorporated into the composite systems. The TA was used as a crosslinker to induce the crosslinking of ESO and form highly tough TA-c-ESO/PLA blend, while the CNTs was expected to impart the obtained CNT/TA-c-ESO/PLA nanocomposites with good mechanical strength and modulus as well as electrical properties. Fixed TA usage (10 wt $\%$ TA-c-ESO with a molar ratio of $-\mathrm{OH}$ to epoxy of 0.6) and various amounts of CNTs (0.5$10 \mathrm{wt} \%$ ) were added into the ESO/PLA products to investigate the influence of CNTs content on the performance of the resulting CNT/TA-c-ESO/PLA nanocomposites. The synergistic effects of CNTs and TAc-ESO on the reinforcing and toughening of the nanocomposites were also investigated.

\section{Materials and methods}

\subsection{Materials}

PLA (Ingeo 3001D) was given by NatureWorks Japan. ESO (epoxy value: $>6$ ) was purchased from Aladdin Industrial Corporation (China). Multiwalled CNTs (NANOCYL ${ }^{\circledR}$ NC7000 ${ }^{\mathrm{TM}}$ ) with an average diameter of $9.5 \mathrm{~nm}$ and an average length of $1.5 \mu \mathrm{m}$ were obtained from Nanocyl Japan. TA was purchased from Nacalai Tesque, INC (Japan).

\subsection{Preparation of CNT/TA-c-ESO/PLA nanocomposites}

The preparation of TA-c-ESO/PLA blends was described in previous work [19]. Briefly, TA-dispersed ESO solution was prepared by dissolving TA $(2.92 \mathrm{~g}$ ) and ESO (17.08 g) (a molar ratio of $-\mathrm{OH}$ groups to epoxy groups of 0.6$)$ in acetone $(20 \mathrm{~g})$. Then, the TA-dispersed ESO solution was mixed with the oven-dried PLA pellets $(180 \mathrm{~g})$ at a weight ratio of 1:9 on a twin-screw extruder (Technovel Corporation Japan) to perform dynamic vulcanization process. The extruded TA-c-ESO/PLA blends were cooled in water and oven-dried for composite preparation.

The obtained TA-c-ESO/PLA blends were mixed with CNTs at different weight ratios of $0.5,1,3,5$, 7 , and $10 \mathrm{wt} \%$, respectively, to fabricate CNT/TAc-ESO/PLA nanocomposites. The nanocomposites were abbreviated as $x \mathrm{CNT} / \mathrm{TA}-\mathrm{c}-\mathrm{ESO} / \mathrm{PLA}$, where the $x$ means the weight fraction of CNTs in the nanocomposites. The mixing process was performed on the same twin-screw extruder as the procedure of TA-c-ESO/PLA blend preparation. Composite specimens were obtained from an injection molding machine (NP7-1F, Nissei Plastic Industrial, Japan). The nozzle temperature and mold temperature were 170 and $40^{\circ} \mathrm{C}$, respectively. Further, specimens from TAc-ESO/PLA blend and PLA nanocomposite with $5 \mathrm{wt} \%$ CNTs (5CNT/PLA) were prepared under same conditions for comparison.

\subsection{Characterization}

The crystallization behavior of the nanocomposites were analyzed by a STA 449 F3 Jupiter Simultaneous Thermal Analyzer (NETZSCH, Germany) from 25 to $210^{\circ} \mathrm{C}$ at a heating rate of $10^{\circ} \mathrm{C} \cdot \mathrm{min}^{-1}$ with $\mathrm{N}_{2}$ protection. The crystallinity $\left(X_{\mathrm{c}}\right)$ of PLA phase was determined as Equation (1) [46]:

$X_{\mathrm{c}}=\frac{\Delta H_{\mathrm{m}}-H_{\mathrm{cc}}}{\Delta H_{100} \cdot x_{\mathrm{PLA}}} \cdot 100$

where $\Delta H_{\mathrm{m}}$ and $\Delta H_{\mathrm{cc}}$ are the enthalpies of melting and cold crystallization detected from differential scanning calorimetry (DSC) tests, respectively; $\Delta H_{100}$ is theoretical enthalpy $\left(93.6 \mathrm{~J} \cdot \mathrm{g}^{-1}\right)$ of a crystalline PLA to melt; $x_{\text {PLA }}$ is the weight ratio of PLA in the nanocomposites. Dynamic mechanical analysis (DMA) was conducted on a RSA-G2 solids analyzer (TA Instrument, USA) according to ASTM D 7028-15. The tests were conducted on rectangular samples $(55 \times$ $10 \mathrm{~mm}^{2}$ ) as the following procedure: three-point 
bending mode; a strain of $0.1 \%$; temperature from 30 to $100^{\circ} \mathrm{C}$ at a scan rate of $2^{\circ} \mathrm{C} \cdot \mathrm{min}^{-1}$; and a frequency of $1 \mathrm{~Hz}$. Thermal stability was tested on a DTG-60 thermogravimetric (TG) instrument (SHIMADZU, Japan) from 30 to $600^{\circ} \mathrm{C}$ at a heating rate of $10^{\circ} \mathrm{C} \cdot \mathrm{min}^{-1}$ with a $\mathrm{N}_{2}$ flow. Tensile properties were tested on a Series 3360 universal testing machine (Instron, USA) according to ASTM D 638-10. Five dumbbell specimens (gauge length: $25 \mathrm{~mm}$; thickness: $2 \mathrm{~mm}$; narrow section width: $5 \mathrm{~mm}$ ) were tested at a crosshead rate of $10 \mathrm{~mm} \cdot \mathrm{s}^{-1}$ for each nanocomposite. Morphologies of the nanocomposites were observed on a JSM-7500F scanning electron microscope (SEM) (JEOL, Japan) and a Tecnai G2 F30 transmission electron microscopy (TEM) (FEI, USA). For SEM observation, the cryo-fractured and tensilefractured surfaces of the samples were coated with a gold film (8 to $10 \mathrm{~nm}$ ). For TEM analysis, ultrathin

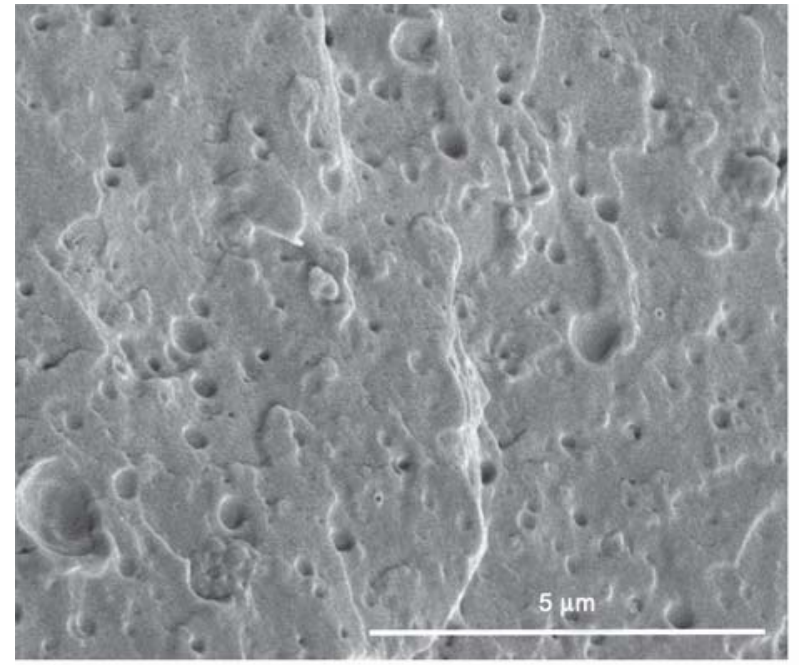

a)

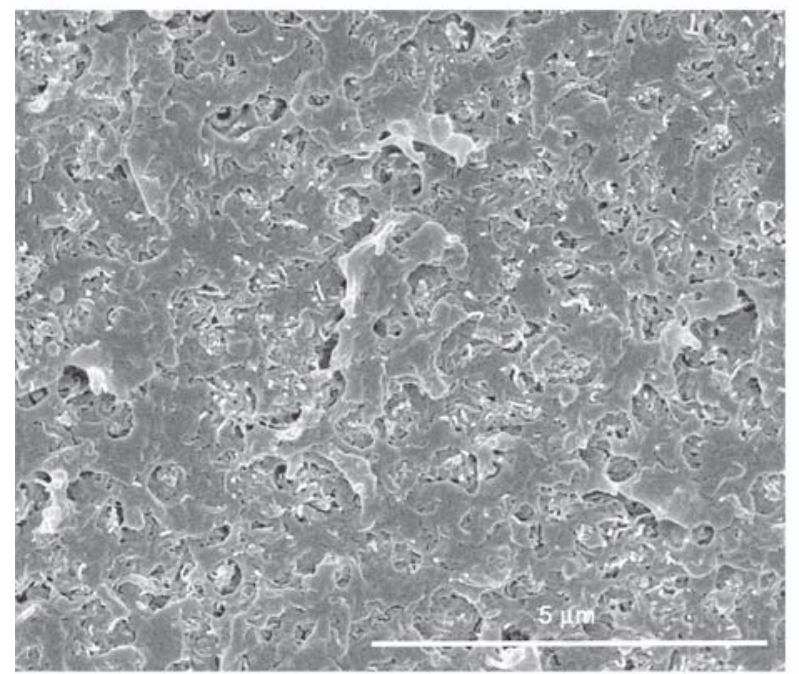

c) samples $(\sim 100 \mathrm{~nm})$ were cryogenically cut at a temperature of $-80^{\circ} \mathrm{C}$ using a Leica EM UC7 ultramicrotome (Germany). The volume electrical conductivity of rectangular samples was measured on an UPMCPHT450 double loop resistance meter (Mitsubishi Chemical Corporation, Japan). Five replicates were conducted for each nanocomposite.

\section{Results and discussions \\ 3.1. Morphological analysis}

The distributions of TA-c-ESO phase and CNTs on the nanocomposites were observed by SEM and TEM. The SEM images of TA-c-ESO/PLA blend and its nanocomposites with $0.5,3$, and $5 \mathrm{wt} \% \mathrm{CNTs}$ from their cryo-fractured specimens were shown in Figure 2. The surface of TA-c-ESO/PLA blend exhibited a typical sea-island morphology as characterized by raised particles and voids due to the dispersed

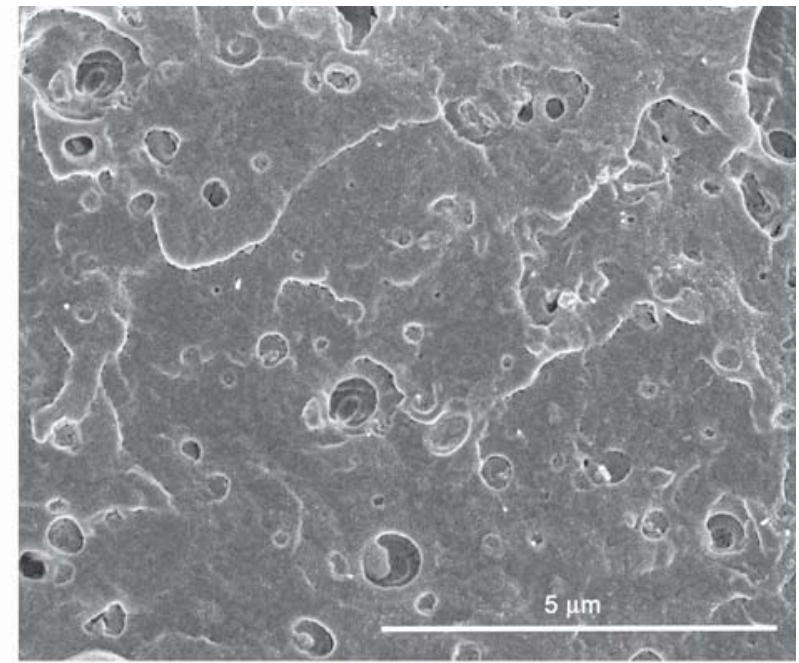

b)

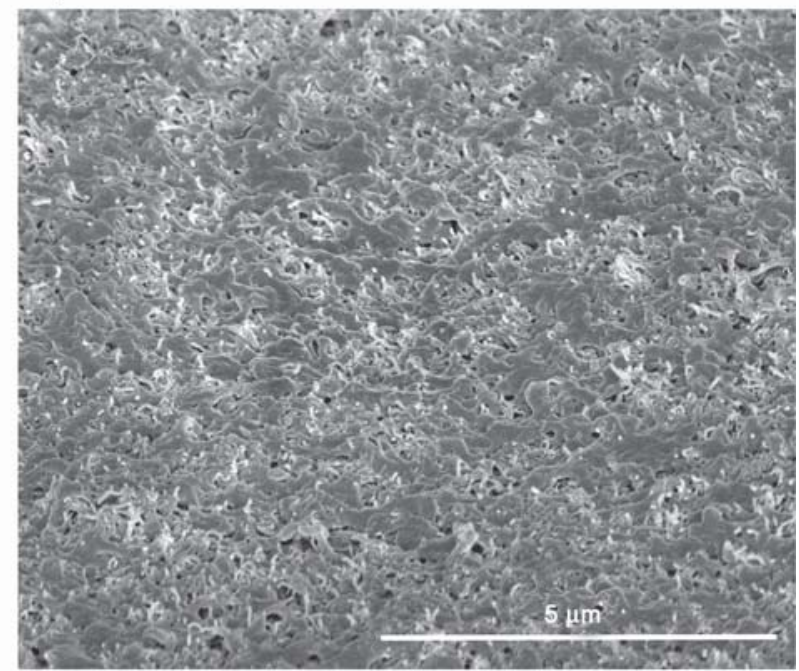

d)

Figure 2. SEM images of cryo-fractured surfaces of (a) TA-c-ESO/PLA blend, (b) 0.5CNT/TA-c-ESO/PLA, (c) 3CNT/TAc-ESO/PLA, and (d) 5CNT/TA-c-ESO/PLA nanocomposites. 
TA-c-ESO phase (Figure 2a). For the nanocomposite with 0.5 wt $\%$ CNTs, a small fraction of CNTs was observed as light spots in the major PLA continuous phase (Figure $2 b$ ) because of the stronger affinity between CNTs and PLA than that between CNTs and TA-c-ESO phase. This can be confirmed by the matched solubility parameters of CNTs and PLA, which are approximately of 17.8 and $18.5 \mathrm{MPa}^{1 / 2}$, respectively [29]. More importantly, the thermoset TAc-ESO phase has a three-dimensional network structure and hence cannot be melted to embed CNTs at high temperature. The size of the TA-c-ESO droplets was significantly reduced after the addition of CNTs. Especially, when the CNTs content increased up to $3 \mathrm{wt} \%$, the TA-c-ESO phase was hardly observed due to its sharply decreased size (Figures 2c, 2d). Meanwhile, large amount of CNTs were distributed and aggregated in the PLA phase. The selective distribution of CNTs in PLA phase tends to form a network structure as the increased CNTs content, which probably absorbs PLA phase around the CNTs networks and inhibits the breakup of PLA phase during processing. Also, the re-processing of the TA-c-ESO/ PLA blend during nanocomposite preparation would reduce the particle size of the TA-c-ESO droplets because of the shear forces originated from the rotating screw.

The TEM images of TA-c-ESO/PLA blend exhibited number of broken cavities resulted from the TA-cESO droplets since the size of the droplets was much higher than the thickness of the prepared sample for TEM analysis (Figures 3a, 3b). This phenomenon was largely eliminated for the $0.5 \mathrm{CNT} / \mathrm{TA}-\mathrm{c}-\mathrm{ESO} /$ PLA nanocomposite due to the decreased particle size of the droplets (Figure 3c); a small part of CNTs was evenly distributed in the nanocomposite (Figure 3d). In agreement with the information from SEM images, more CNTs were distributed and aggregated in the nanocomposites when the CNTs content increased to 3 and $5 \mathrm{wt} \%$ (Figures 3e, 3f). The aggregation of CNTs in the nanocomposites was observed because of the poor interfacial adhesion between the pristine CNTs and PLA matrix, indicating that further functionalization for CNTs is desired for the nanocomposites to achieve higher performance.

\subsection{Crystallization behavior}

The TA-c-ESO/PLA blend and its nanocomposites with CNTs were analyzed by DSC analysis to reveal their thermal transition and crystallization characteristics (Figure 4 and Table 1). Relative to pure PLA,
TA-c-ESO/PLA blend showed significantly reduced glass transition temperature $\left(T_{\mathrm{g}}\right)$ and cold crystallization temperature $\left(T_{\mathrm{cc}}\right)$ as well as improved crystallinity $\left(X_{\mathrm{c})}\right.$. The reduced $T_{\mathrm{g}}$ and $T_{\mathrm{cc}}$ are explained by the plasticizing effect of TA-c-ESO phase, where the TAc-ESO oligomers would exist between PLA molecular chains and hence improve their mobility at low temperature [10]. The increased $X_{\mathrm{c}}$ is probably due to the heterogeneous nucleation effect of the added TA-c-ESO particles for the crystallization of PLA. Furthermore, the introduction of CNTs into TA-cESO/PLA blend did not significantly change the $T_{\mathrm{g}}$ of the resulting nanocomposites. Slight decreases in $T_{c \mathrm{c}}$ and cold crystallization enthalpy $\left(\Delta H_{\mathrm{cc}}\right)$ were observed from the nanocomposites compared to TA-cESO/PLA blend because the added CNTs could act as a nucleating agent and induce crystallization. This also explains the slightly increased $X_{\mathrm{c}}$ of the nanocomposite from 28.51 to $31.41 \%$ after the introduction of $0.5 \mathrm{wt} \% \mathrm{CNTs}$. However, the agglomeration of excess CNTs would prevent the growth of the crystal nucleus and hence reduce the ability of inducing crystallization, which was confirmed by the decreased $X_{\mathrm{c}}$ of the nanocomposites when increasing CNTs usage up to $3 \mathrm{wt} \%$. The melting of crystalline PLA phase presented a single melting temperature $\left(T_{\mathrm{m}}\right)$ around $170^{\circ} \mathrm{C}$ for all the blends and nanocomposites, which was not significantly affected by the addition of TA-c-ESO phase and CNTs. The melting enthalpy $\left(\Delta H_{\mathrm{m}}\right)$ of TA-c-ESO/PLA blend was higher than that of pure PLA because of the enhanced $X_{\mathrm{c}}$. However, the incorporation of CNTs caused slight reduction in the $\Delta H_{\mathrm{m}}$ because of the reduced relatively amount of crystalline region of PLA in the nanocomposites.

As for the 5CNT/PLA nanocomposite, increases in $T_{\mathrm{g}}$ and $X_{\mathrm{c}}$ were observed along with decreases in $T_{\mathrm{cc}}$, $\Delta H_{\mathrm{cc}}$, and $\Delta H_{\mathrm{m}}$ when compared to neat PLA due to the reinforcing and nucleation effects of CNTs on PLA. These effects are in agreement with the influence of CNTs on TA-c-ESO/PLA blend with a diminished degree. This confirms that the flexible TAc-ESO rubbery phase has a significant effect on the crystallization behavior of nanocomposites.

\subsection{Dynamic mechanical properties}

The storage modulus $\left(E^{\prime}\right)$ curves for all the nanocomposites had a platform from 35 to $50^{\circ} \mathrm{C}$ and subsequently experienced a dramatic drop at the temperatures from 50 to $65^{\circ} \mathrm{C}$, which is resulted from 

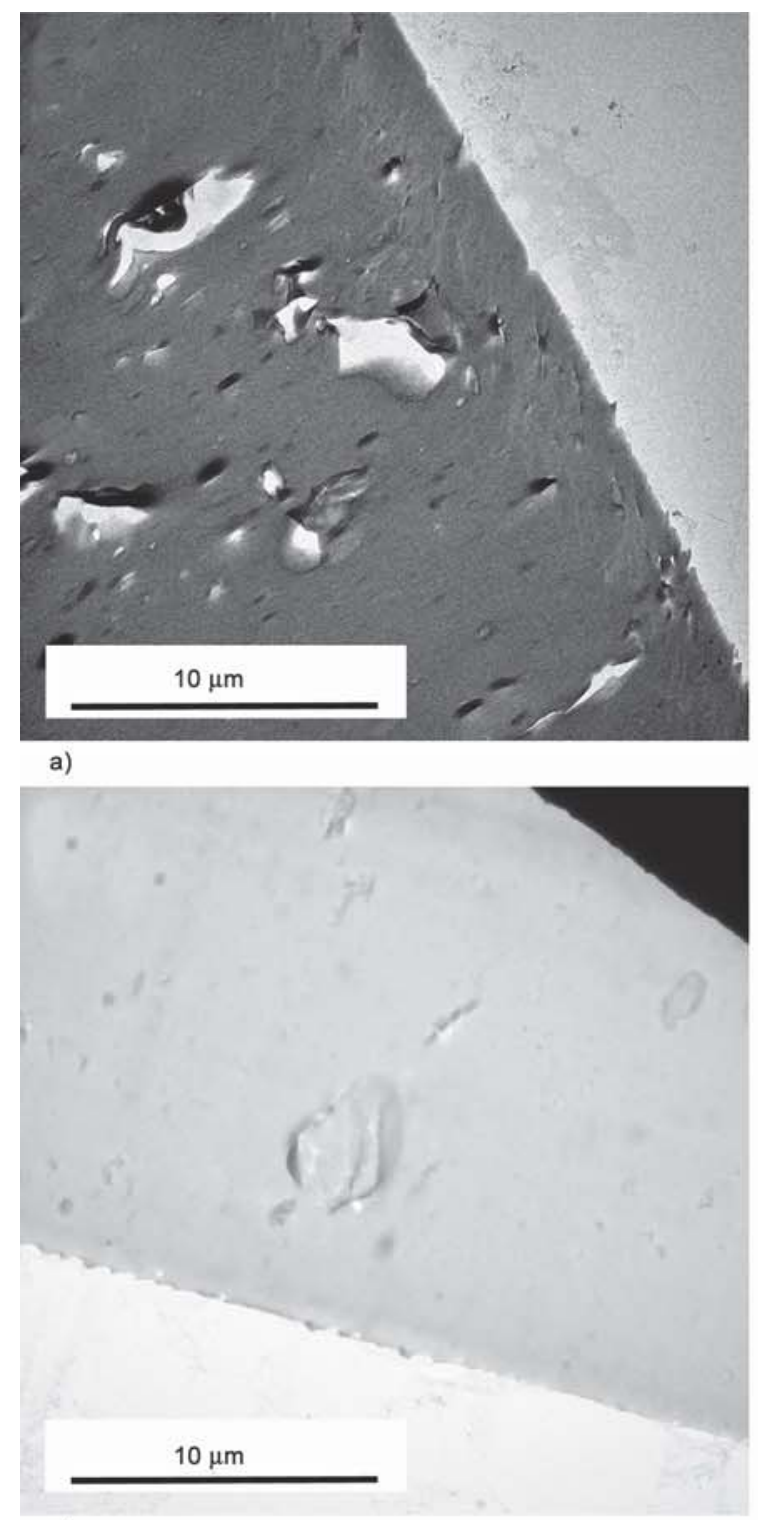

c)

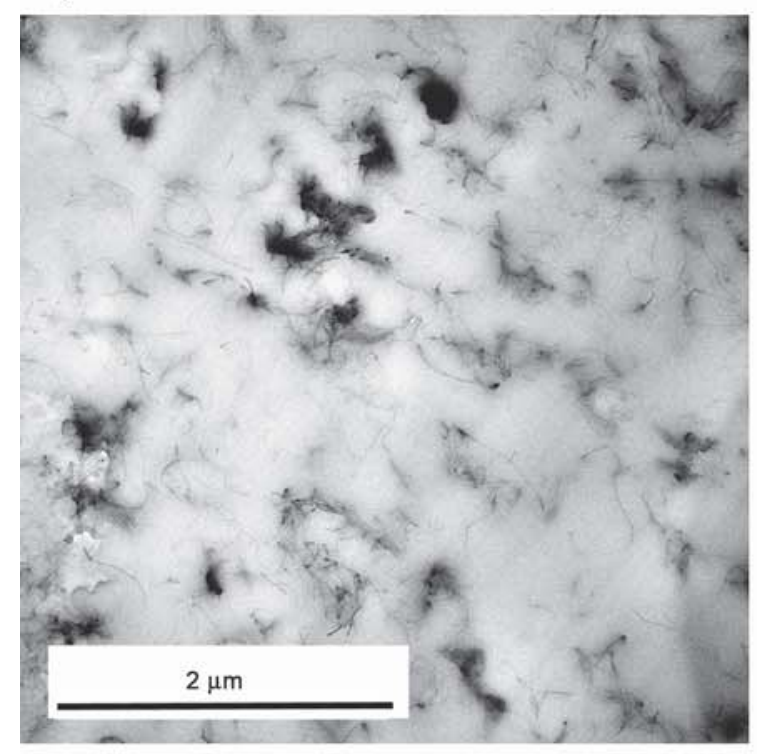

e)

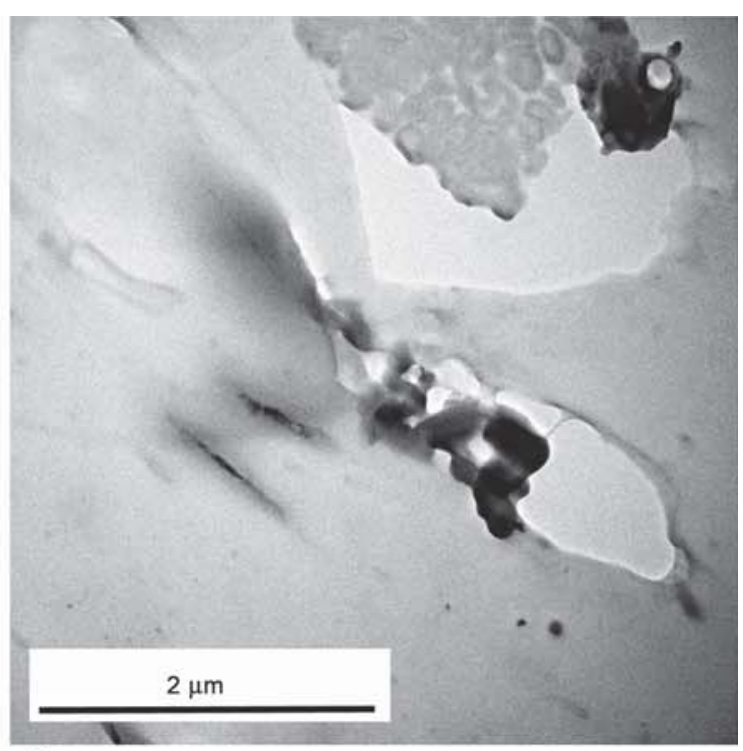

b)
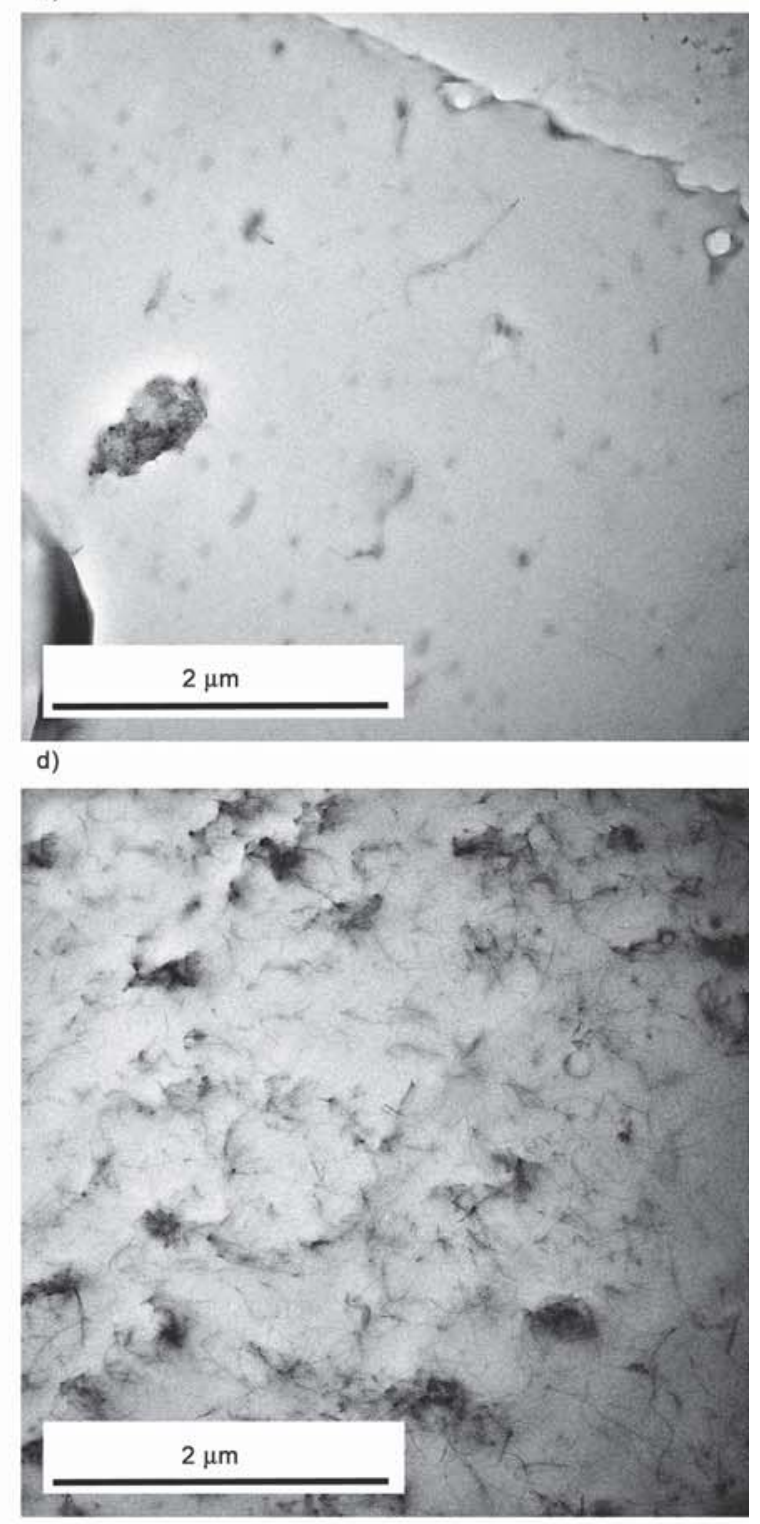

Figure 3. TEM images of (a, b) TA-c-ESO/PLA blend, (c, d) 0.5CNT/TA-c-ESO/PLA, (e) 3CNT/TA-c-ESO/PLA, and (f) 5CNT/TA-c-ESO/PLA nanocomposites. 


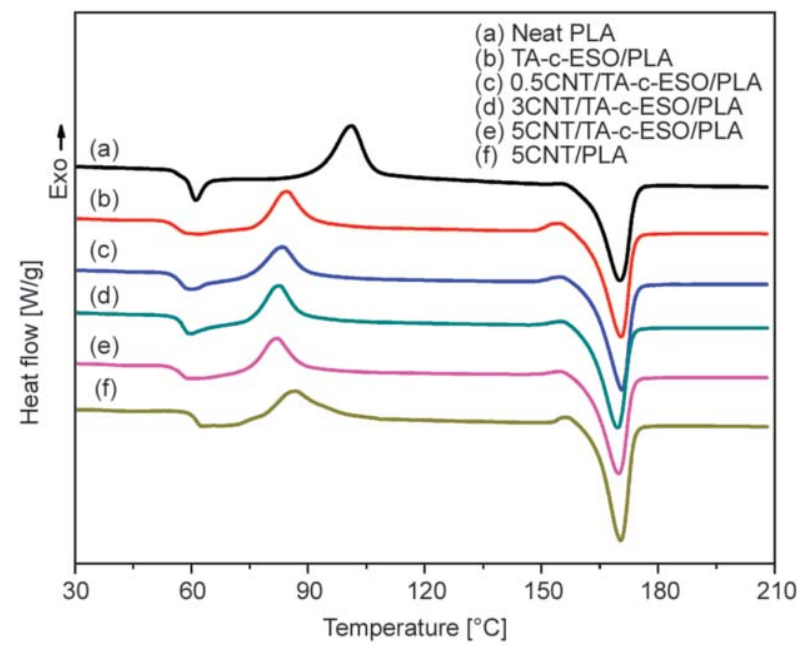

Figure 4. DSC curves of neat PLA, TA-c-ESO/PLA, CNT/ PLA and CNT/TA-c-ESO/PLA nanocomposites.

the glass transition behavior (Figure 5a). The characteristic results of DMA analysis were summarized in Table 2. The $E^{\prime}$ of TA-c-ESO/PLA blend at $35^{\circ} \mathrm{C}$ was $2.67 \mathrm{GPa}$, much lower than that of pure PLA (3.19 GPa) due to the plasticization effect of TA-cESO phase [19]. The addition of CNTs into the blend resulted in increments in the $E^{\prime} \mathrm{s}$ of the resulting nanocomposites. The $E^{\prime} \mathrm{s}$ of the nanocomposites at $35^{\circ} \mathrm{C}$ increased from 2.79 to $3.20 \mathrm{GPa}$ with the increasing CNTs usage from 0.5 to $5 \mathrm{wt} \%$. This is attributed to the strengthening effect of CNTs that has extremely high strength and modulus. Further, the 5CNT/TA-c-ESO/PLA nanocomposite has a slightly lower $E^{\prime}$ than 5CNT/PLA nanocomposite because of the added TA-c-ESO rubbery phase that reduces the stiffness of the nanocomposite.

The loss modulus $\left(E^{\prime \prime}\right)$ of TA-c-ESO/PLA blend showed two modulus peaks due to the flowability of molecular chains (Figure 5b), which corresponds to the glass transition behavior of the polymer and the rearrangement of polymer chains from amorphous areas into crystalline phase, respectively [47]. The incorporation of CNTs did not significantly change the transition temperatures of the nanocomposites, but increased the intensity of the second transition peak at high temperature region. This indicates that the added CNTs could facilitate the segmental movements of movable and amorphous areas because of its heterogeneous nucleation effect, which is in agreement with the reduced $T_{\mathrm{cc}}$ obtained from DSC analyses as the increase of CNTs usage.

The damping parameter $(\tan \delta)$ peak of TA-c-ESO/ PLA blend was intensive and has higher peak height and area than those of the nanocomposites (Figure $5 \mathrm{c}$ ), indicating a superior molecular flowability resulted from the toughening of TA-c-ESO phase. The peak height and area of the nanocomposites significantly decreased with the increase of CNTs content, indicative of a reduced damping capacity due to the improved stiffness. The peak temperature of $\tan \delta$ curve was generally considered as the $T_{\mathrm{g}}$. The $T_{\mathrm{g}} \mathrm{S}$ of all the CNT/TA-c-ESO/PLA nanocomposites were comparable with that of TA-c-ESO/PLA blend, but significantly lower than that of 5CNT/PLA nanocomposite. This demonstrates that the ability of CNTs in improving the $T_{\mathrm{g}}$ of PLA nanocomposites is completely overcompensated by the weakening effect of the ductile TA-c-ESO phase. The results are in accordance with that from DSC scans, although their $T_{\mathrm{g}} \mathrm{s}$ were slightly higher than those from DSC tests because of the different basic theories of these two technologies.

\subsection{Thermal stability}

The TG and DTG curves of TA-c-ESO/PLA blend and its nanocomposites with CNTs and their characteristic weight loss temperatures were shown in Figure 6 and Table 3. To evaluate the overall thermal resistance of the nanocomposites, a heat-resistant index $\left(T_{\mathrm{s}}\right)$ was proposed as Equation (2) [48]:

$T_{\mathrm{s}}=0.49\left[T_{5}+0.6\left(T_{30}-T_{5}\right)\right]$

where $T_{5}$ and $T_{30}$ were the 5 and $30 \%$ weight loss temperatures, respectively; $T_{\max }$ was the maximum weight loss temperature. It is noted that the thermal

Table 1. DSC results of neat PLA, TA-c-ESO/PLA, CNT/PLA and CNT/TA-c-ESO/PLA nanocomposites.

\begin{tabular}{|l|c|c|c|c|c|c|}
\hline \multicolumn{1}{|c|}{ References } & $\begin{array}{c}\boldsymbol{T}_{\mathbf{g}} \\
{\left[{ }^{\circ} \mathbf{C}\right]}\end{array}$ & $\begin{array}{c}\boldsymbol{T}_{\text {cc }} \\
{\left[{ }^{\circ} \mathbf{C}\right]}\end{array}$ & $\begin{array}{c}\boldsymbol{T}_{\mathbf{m}} \\
{\left[{ }^{\circ} \mathbf{C}\right]}\end{array}$ & $\begin{array}{c}\Delta \boldsymbol{H}_{\mathbf{c c}} \\
{\left[\mathbf{J} \cdot \mathbf{g}^{-1}\right]}\end{array}$ & $\begin{array}{c}\Delta \boldsymbol{H}_{\mathbf{m}} \\
{\left[\mathbf{J} \cdot \mathbf{g}^{-\mathbf{1}}\right]}\end{array}$ & $\begin{array}{c}\boldsymbol{X} \\
{[\%]}\end{array}$ \\
\hline Neat PLA & 61.15 & 101.07 & 170.18 & 23.73 & 37.81 & 14.93 \\
\hline TA-c-ESO/PLA & 58.37 & 84.29 & 170.48 & 17.33 & 41.19 & 28.33 \\
\hline 0.5CNT/TA-c-ESO/PLA & 58.74 & 83.60 & 170.84 & 14.28 & 40.44 & 31.21 \\
\hline 3CNT/TA-c-ESO/PLA & 59.47 & 82.49 & 169.38 & 14.74 & 37.92 & 28.37 \\
\hline 5CNT/TA-c-ESO/PLA & 59.10 & 81.76 & 169.75 & 14.62 & 37.46 & 28.54 \\
\hline 5CNT/PLA & 63.14 & 86.49 & 170.11 & 19.06 & 40.61 & 24.23 \\
\hline
\end{tabular}



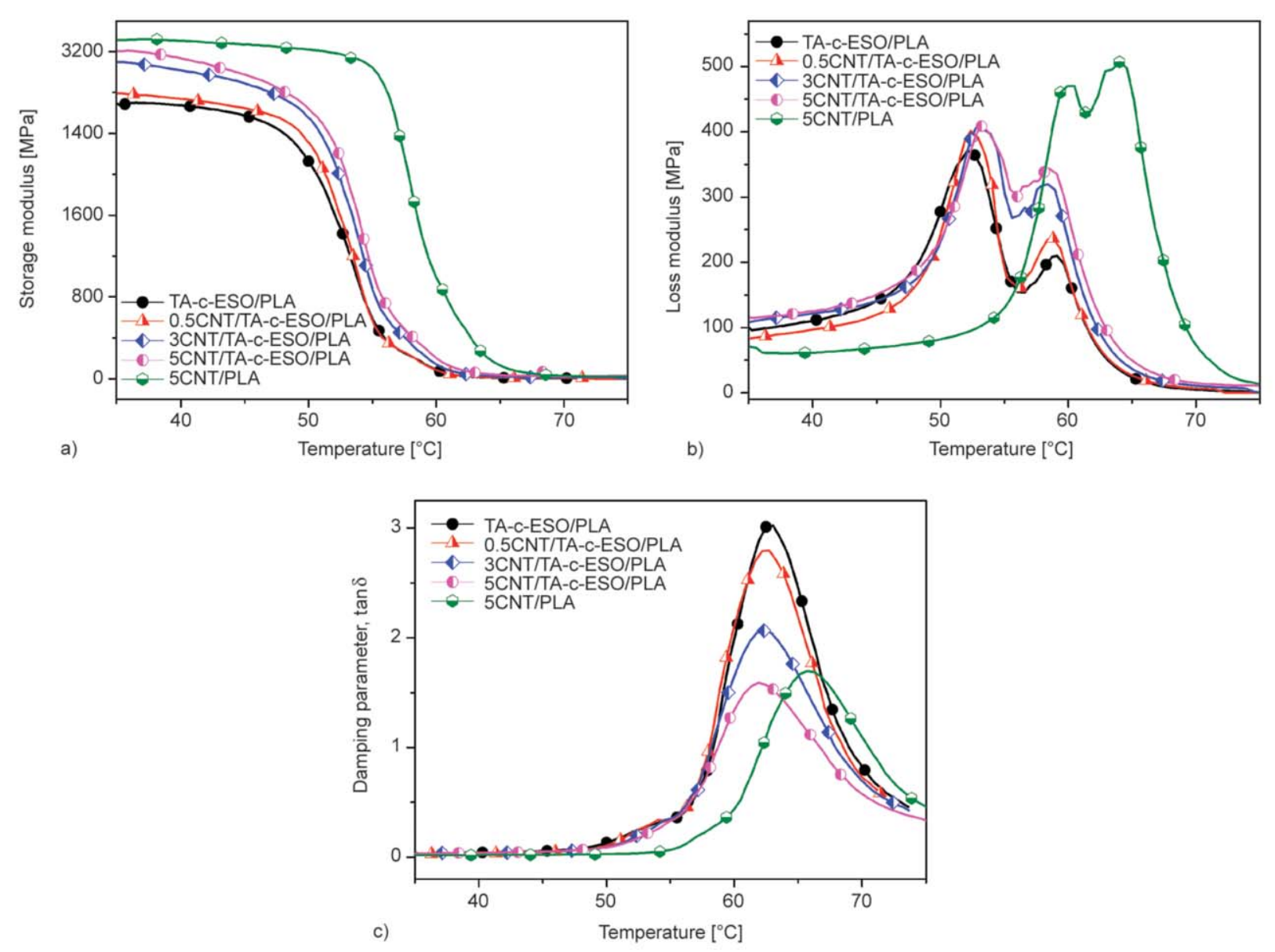

Figure 5. DMA curves of TA-c-ESO/PLA, CNT/PLA and CNT/TA-c-ESO/PLA nanocomposites. (a) Storage modulus; (b) loss modulus; (c) damping parameter.

Table 2. DMA data of TA-c-ESO/PLA, CNT/PLA and CNT/TA-c-ESO/PLA nanocomposites.

\begin{tabular}{|c|c|c|c|c|}
\hline \multirow[t]{2}{*}{ Reference } & \multirow{2}{*}{$\begin{array}{c}\text { Storage modulus at } \\
35^{\circ} \mathrm{C} \\
{[\mathrm{GPa}]}\end{array}$} & \multicolumn{2}{|c|}{$\begin{array}{l}\text { Peak temperatures from loss modulus } \\
\qquad\left[{ }^{\circ} \mathrm{C}\right]\end{array}$} & \multirow{2}{*}{$\begin{array}{c}T_{\mathrm{g}} \text { from } \tan \delta \\
{\left[{ }^{\circ} \mathrm{C}\right]}\end{array}$} \\
\hline & & Peak 1 & Peak 2 & \\
\hline TA-c-ESO/PLA & 2.67 & 52.22 & 59.11 & 62.76 \\
\hline $0.5 \mathrm{CNT} / \mathrm{TA}-\mathrm{c}-\mathrm{ESO} / \mathrm{PLA}$ & 2.79 & 52.44 & 58.75 & 62.43 \\
\hline 3CNT/TA-c-ESO/PLA & 3.10 & 52.93 & 58.36 & 62.32 \\
\hline 5CNT/TA-c-ESO/PLA & 3.20 & 53.32 & 58.55 & 61.99 \\
\hline 5CNT/PLA & 3.31 & 60.18 & 64.06 & 65.86 \\
\hline
\end{tabular}

stability of the nanocomposites was slightly improved after the addition of CNTs. The $T_{\max } \mathrm{s}$ of the nanocomposites increased from 364.9 to $367.4{ }^{\circ} \mathrm{C}$ with the increase of CNTs from 0.5 to $5 \mathrm{wt} \%$, although the $T_{\mathrm{S}} \mathrm{s}$ of the nanocomposites were not significantly affected by the CNTs content. It is reported that the added CNTs would provide tortuous paths and barrier effects against the volatile pyrolysis products of PLA, which effectively prevents the diffusion of oxygen into the polymer matrices and thus the thermal degradation of the nanocomposites [43, 49]. Furthermore, in comparison with 5CNT/PLA nanocomposite, 5CNT/TA-c-ESO/PLA nanocomposite exhibited an improved thermal stability because of its significantly higher $T_{\mathrm{s}}$. The functional groups of the main components in the polymer matrix significantly affect the thermal decomposition of the nanocomposites. Both ESO molecules with aliphatic chains and TA monomers with aromatic rings have higher thermal resistance than PLA chains with a large number of ester groups, which is responsible for the enhanced thermal resistance of the nanocomposites in the presence of TA-c-ESO phase. 

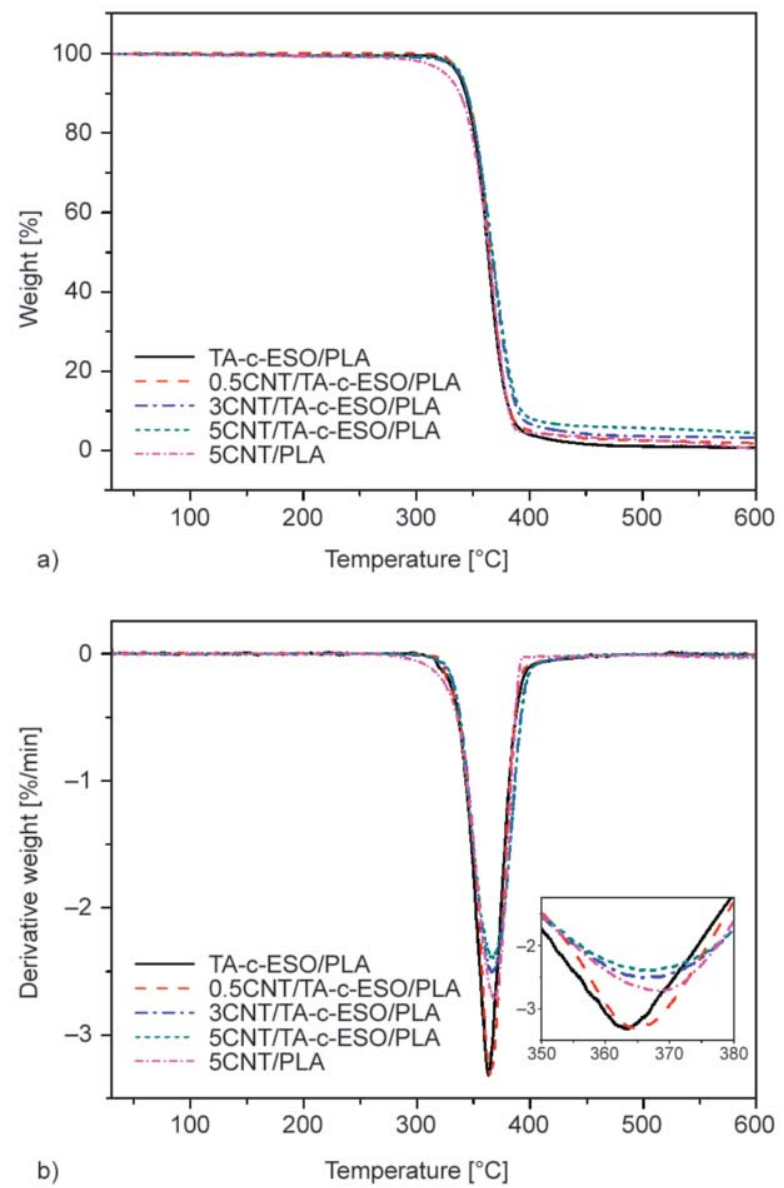

Figure 6. Thermal degradation behaviors of TA-c-ESO/ PLA, CNT/PLA and CNT/TA-c-ESO/PLA nanocomposites. (a) TG curves; (b) DTG curves.

Table 3. Characteristic weight loss temperatures of TA-cESO/PLA, CNT/PLA and CNT/TA-c-ESO/PLA nanocomposites.

\begin{tabular}{|c|c|c|c|c|}
\hline \multirow[t]{2}{*}{ References } & \multicolumn{3}{|c|}{$\begin{array}{c}\text { Characteristic weight loss } \\
\text { temperature } \\
{\left[{ }^{\circ} \mathrm{C}\right]} \\
\end{array}$} & \multirow[t]{2}{*}{$\begin{array}{c}\boldsymbol{T}_{\mathrm{s}} \\
{\left[{ }^{\circ} \mathbf{C}\right]}\end{array}$} \\
\hline & $T_{\max }$ & $T_{5}$ & $T_{30}$ & \\
\hline TA-c-ESO/PLA & 363.4 & 336.6 & 356.1 & 170.7 \\
\hline $0.5 \mathrm{CNT} / \mathrm{TA}-\mathrm{c}-\mathrm{ESO} / \mathrm{PLA}$ & 364.9 & 338.4 & 357.8 & 171.5 \\
\hline 3CNT/TA-c-ESO/PLA & 367.6 & 338.1 & 357.9 & 171.5 \\
\hline 5CNT/TA-c-ESO/PLA & 367.4 & 339.1 & 358.1 & 171.7 \\
\hline 5CNT/PLA & 368.8 & 325.5 & 335.0 & 162.3 \\
\hline
\end{tabular}

\subsection{Tensile properties}

Figure 7 shows the stress-strain curves of TA-c-ESO/ PLA blend and its nanocomposites with $0.5,3$, and 5 wt $\%$ CNTs. TA-c-ESO/PLA blend exhibited ductile characters with clear yield point and cold-drawing region, while the characters for the nanocomposites gradually mitigated with the increase of CNTs content. 5CNT/PLA nanocomposite showed a typical brittle fracture behavior due to the brittleness nature

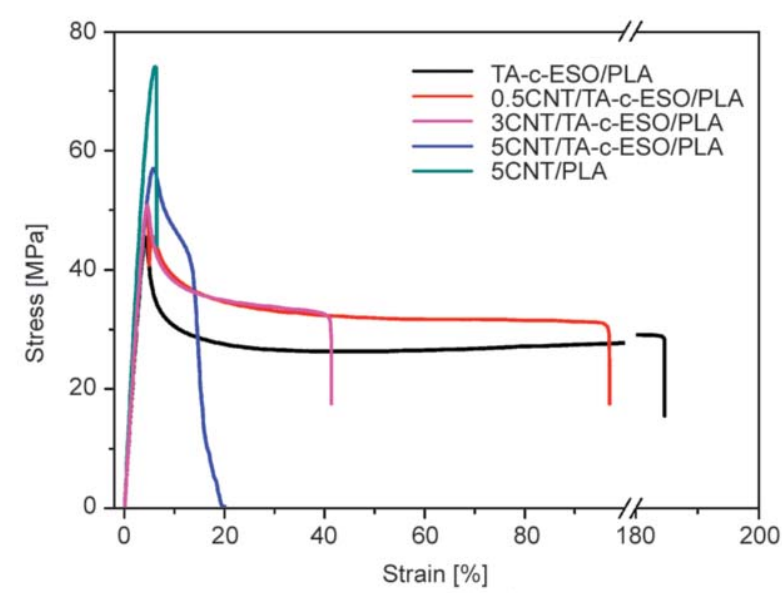

Figure 7. Stress-strain curves of TA-c-ESO/PLA, CNT/PLA and CNT/TA-c-ESO/PLA nanocomposites.

of PLA and reinforcing effect of CNTs. However, the 5CNT/TA-c-ESO/PLA nanocomposite presented obvious yield point and subsequent stress drop region due to the toughening effect of TA-c-ESO rubbery phase.

The tensile strength, modulus, toughness (calculated from the area under the stress-strain curve), and fracture elongation of the nanocomposites are shown in Figure 8. High fracture elongation (186.1\%) and tensile toughness $\left(52.8 \mathrm{MJ} \cdot \mathrm{m}^{-3}\right)$ was achieved for the TA-c-ESO/PLA blend with low tensile strength (45.9 MPa) and tensile modulus (1.3 GPa). This indicates that the presence of TA-c-ESO phase induced the deterioration of strength and modulus of the blend. The strength and modulus can be compensated by the addition of CNTs due to its good strengthening effect. The tensile strength and modulus of the nanocomposites greatly increased from 50.5 to 63.2 $\mathrm{MPa}$ and 1.34 to $1.65 \mathrm{GPa}$, respectively, with the increasing of CNTs usage from 0.5 to $10 \mathrm{wt} \%$. However, the addition of CNTs resulted in dramatic decrease in tensile ductility of the nanocomposites. The fracture elongation and tensile toughness of the nanocomposites dramatically reduced from 95.4 to $19.0 \%$ and 31.6 to $6.9 \mathrm{MJ} \cdot \mathrm{m}^{-3}$, respectively, when the CNTs content increased from 0.5 to $5 \mathrm{wt} \%$; further increase in CNTs concentration from 5 to $10 \mathrm{wt} \% \mathrm{did}$ not significantly affect the fracture elongation and tensile toughness of the nanocomposites. The agglomerates of large CNTs function as the stress concentrator and thus lead to the failure of the nanocomposites during the tension process; also, the formation of a dense CNTs network structure in the nanocomposites inhibits the plastic flow of PLA macromolecules along the tensile direction [44]. Although the 

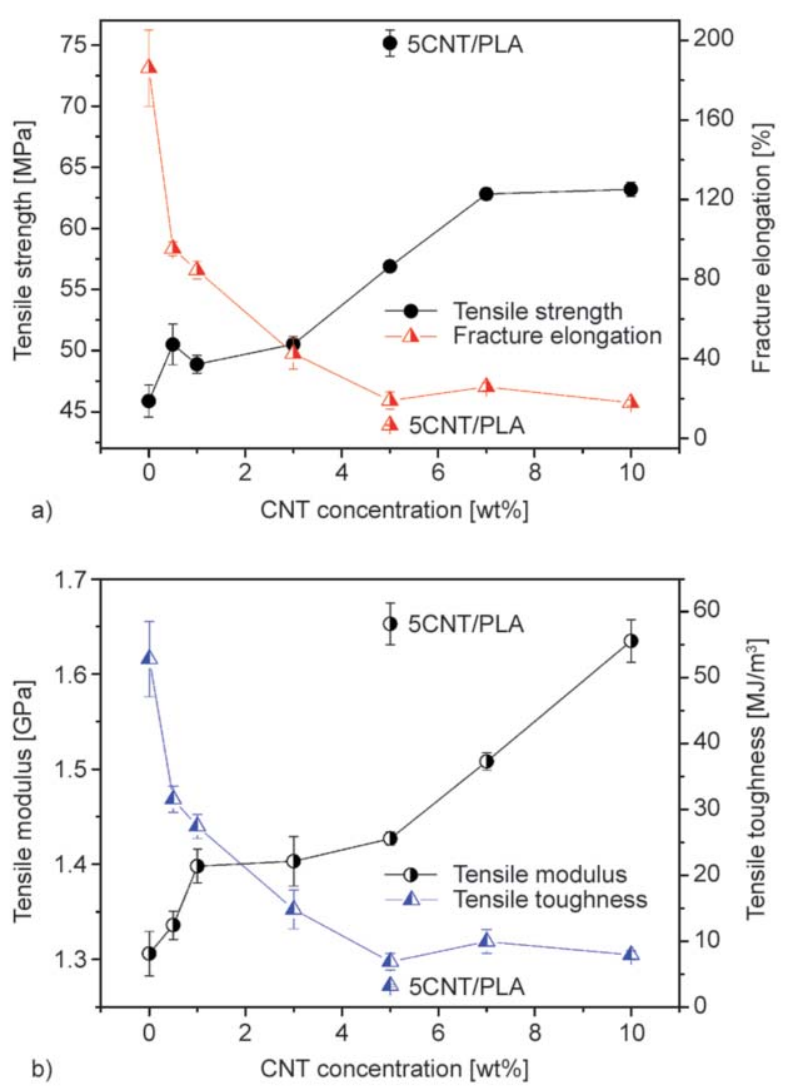

Figure 8. Tensile strength with fracture elongation (a) and tensile modulus, with tensile toughness (b) of TA-c-ESO/PLA, CNT/PLA and CNT/TA-c-ESO/ PLA nanocomposites.

introduction of CNTs into TA-c-ESO/PLA blend causes significant deterioration in toughness, the tensile ductility of 5CNT/TA-c-ESO/PLA nanocomposite still keeps at a relatively high level when compared to that of 5CNT/PLA nanocomposite. In summary, the 5CNT/TA-c-ESO/PLA nanocomposite achieved balanced tensile properties with higher elongation at break and tensile toughness as well as lower tensile strength and modulus in comparison to 5CNT/PLA nanocomposite, which is resulted from the synergistic effects of CNTs reinforcement and TA-c-ESO phase induced toughness.

\subsection{Reinforcing and toughening mechanism}

To reveal the reinforcing and toughening mechanism of CNTs and TA-c-ESO phase on the nanocomposites, SEM images of the tensile-fractured surfaces were given in Figure 9. Briefly, the SEM image of TA-c-ESO/PLA blend was not given. With a tensile loading, the dispersed TA-c-ESO particles in PLA matrix would be debonded, hence causing shear yielding, forming cavities and plastic deformation
$[15,50]$. Similar to TA-c-ESO/PLA blend, the 0.5CNT/TA-c-ESO/PLA nanocomposite still showed amounts of elongated cells with significant plastic deformation (Figures 9a, 9b) [19]. From the SEM images with low magnifications (Figures 9a, 9c, 9e), it is clearly seen that the fractured surfaces of the nanocomposites changed from smooth morphology to coarse surface with the increase of CNTs usage, and obvious and huge holes were shown on the nanocomposites with high CNTs content. These indicate that the aggregation of CNTs at a high content in PLA phase would act directly on the stress concentration region, hence retarding the toughening effect of TA-c-ESO phase on PLA blends. Therefore, the shear yielding phenomenon caused by TA-c-ESO phase are inhibited during the loading process, which can be confirmed by the SEM images with high magnifications for the flat surface region of the nanocomposites (Figures 9b, 9d, 9f). The average size of the elongated cells and cavities reduced with the increasing of CNTs concentration from 0.5 to $5 \mathrm{wt} \%$, indicating a decreased degree of plastic deformation. This is in agreement with the decreased fracture elongation of the nanocomposites as the increase of CNTs usage.

\subsection{Electrical properties}

The electrical conductivity of the CNT/TA-c-ESO/ PLA nanocomposites increased exponentially with the increase of CNTs concentration (Figure 10). For the formation of an electrical conductive pathway constructed in the polymer composites, the distance between CNTs should be very close such that electron can be activated by thermal vibration, go across the polymer barrier, and thus transfer to the adjacent CNTs to form a tunneling current [39]. The percolation threshold $\left(p_{\mathrm{c}}\right)$ was calculated by fitting the dependence of the measured electrical conductivity $(\rho)$ on CNTs content $(p)$ according to classical percolation theory $[39,51]$ (Equation (3)):

$\rho=\sigma_{0}\left(p-p_{c}\right)^{\mathrm{t}}$

where $\sigma_{0}$ is a scaling factor, and $t$ is a percolation exponent. The values of $t$ were generally around 1.3 and 2 for two- and three-dimensions of the percolation network, respectively. The $p_{\mathrm{c}}$ and $t$ values of the CNT/ TA-c-ESO/PLA nanocomposites were estimated to be 6.38 and $2.25 \mathrm{wt} \%$, respectively, which confirms the formation of an approximate three-dimensional 


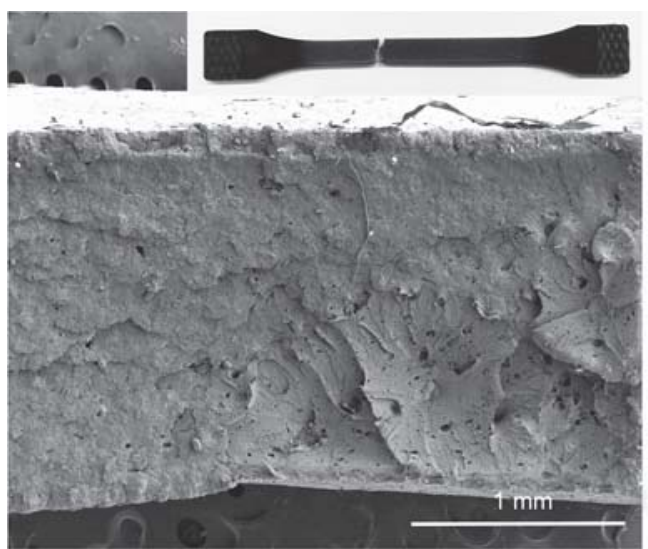

a)

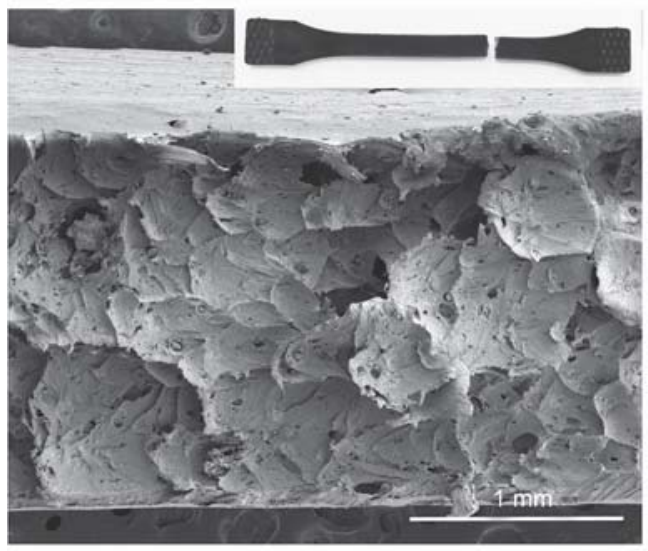

c)

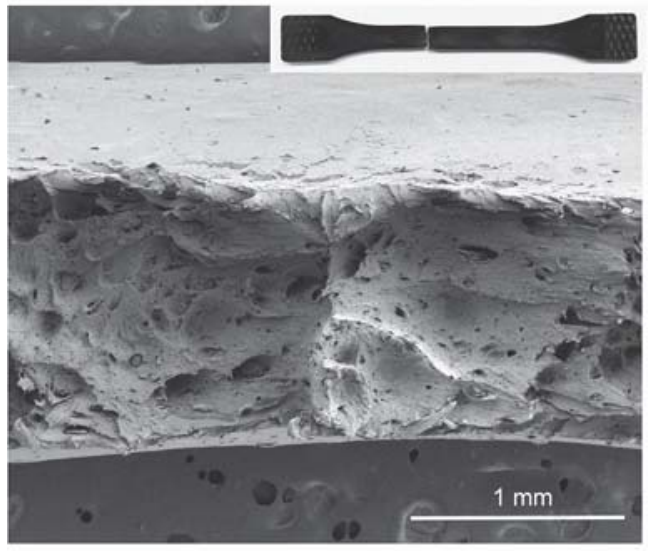

e)

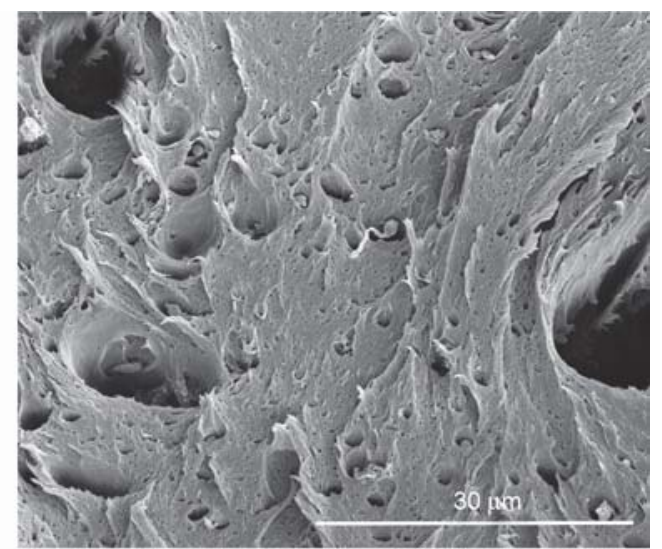

b)

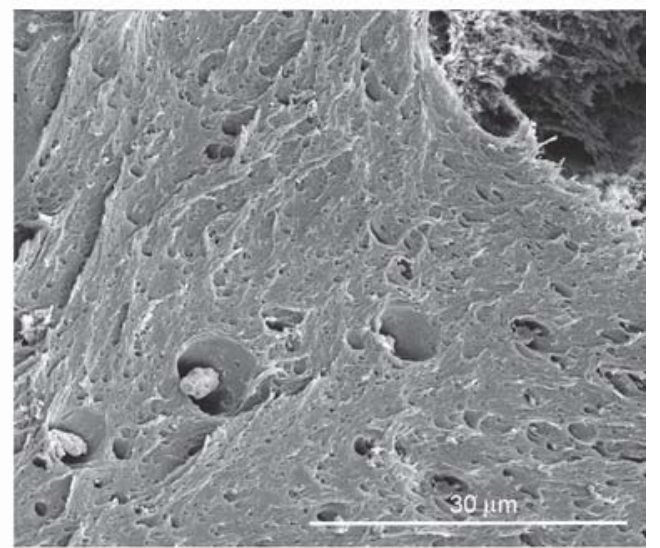

d)

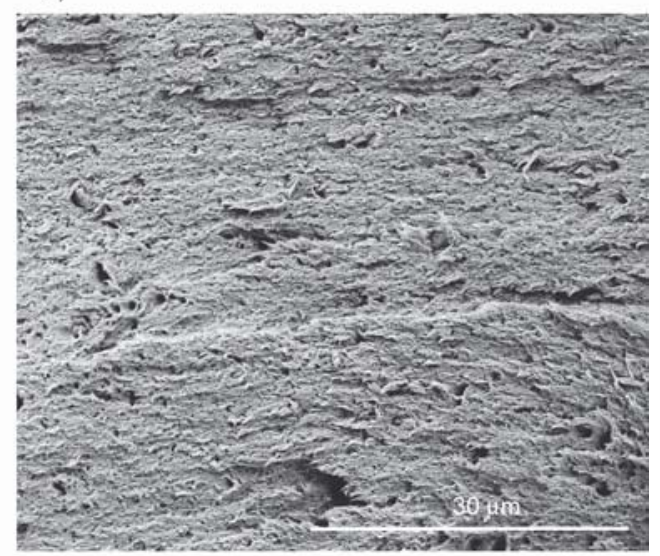

f)

Figure 9. SEM images of tensile-fractured surfaces of (a, b) 0.5CNT/TA-c-ESO/PLA, (c, d) 3CNT/TA-c-ESO/PLA, and (e, f) $5 \mathrm{CNT} / \mathrm{TA}-\mathrm{c}-\mathrm{ESO} / \mathrm{PLA}$ nanocomposites.

conductive network in the nanocomposites. Moreover, the electrical conductivity of 5CNT/TA-c-ESO/ PLA nanocomposite was slightly higher than that of 5CNT/PLA nanocomposite. As revealed by SEM and TEM images, the morphology of TA-c-ESO/PLA blend was a typical sea-island structure with PLA as a continuous phase and TA-c-ESO as a dispersed phase; the added CNTs were mostly distributed in the PLA phase for the CNT/TA-c-ESO/PLA nanocomposites. Therefore, CNTs is slightly easier to connect to each other and then form a conductive network in the CNT/TA-c-ESO/PLA nanocomposite via continuous PLA phase relative to the CNT/PLA nanocomposite when the same loading of CNTs was incorporated.

\section{Conclusions}

High biobased content, strength-toughness balanced, and electrically conductive CNT/TA-c-ESO/PLA nanocomposites were fabricated by dynamic vulcanization of PLA with ESO by using TA as a crosslinker and CNTs as reinforcement. Results indicated that 


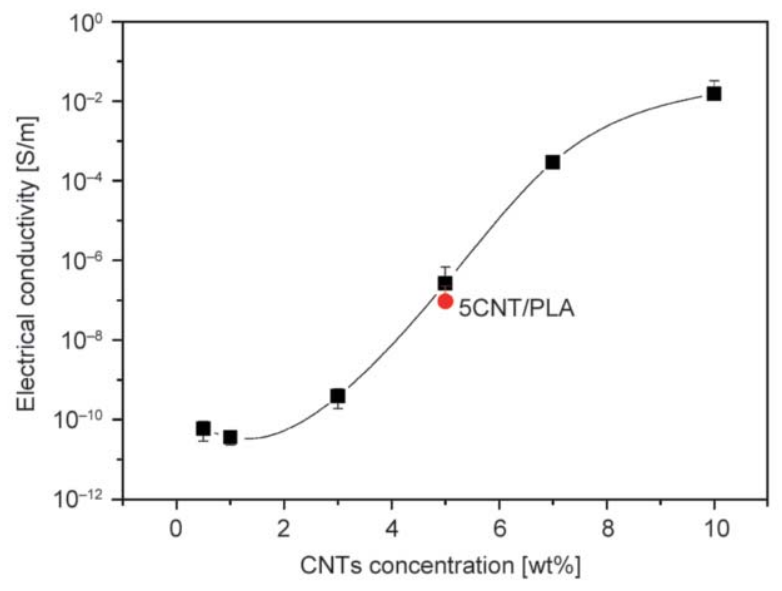

Figure 10. Electrical conductivity of CNT/TA-c-ESO/PLA nanocomposites.

the obtained TA-c-ESO/PLA blend presented a typical sea-island structure and the incorporated CNTs were mainly dispersed in the continuous PLA phase. The combination of TA-c-ESO phase and CNTs resulted in an improved crystallinity of PLA phase due to their heterogeneous nucleation effects. The tensile strength and modulus, storage modulus, and thermal stability of the nanocomposites were increased with the introduction of CNTs; however, the added CNTs led to significant decreases in fracture elongation, tensile toughness, and damping ability of the nanocomposites. This indicated that the toughening effect of TA-c-ESO phase was reduced by the addition of stiff CNTs. The formed sea-island structure in TA-c$\mathrm{ESO} / \mathrm{PLA}$ blends contributed to improving the electrical conductivity of the nanocomposites. The PLA nanocomposites having $10 \mathrm{wt} \%$ TA-c-ESO phase and $5 \mathrm{wt} \%$ CNTs achieved the optimum strengthtoughness balance and favorable electrical conductivity. In a word, a facile and cost-effective method to toughen and strengthen PLA products was provided by using TA to induce crosslinking of ESO and CNTs as reinforcing fillers.

\section{Acknowledgements}

We thank the funding from Fujian Agriculture and Forestry University (Grant No. KXB16007A).

\section{References}

[1] Nagarajan V., Mohanty A. K., Misra M.: Perspective on polylactic acid (PLA) based sustainable materials for durable applications: Focus on toughness and heat resistance. ACS Sustainable Chemistry and Engineering, 4, 2899-2916 (2016).

https://doi.org/10.1021/acssuschemeng.6b00321
[2] Hamad K., Kaseem M., Ayyoob M., Joo J., Deri F.: Polylactic acid blends: The future of green, light and tough. Progress in Polymer Science, 85, 83-127 (2018). https://doi.org/10.1016/j.progpolymsci.2018.07.001

[3] Hamad K., Kaseem M., Yang H. W., Deri F., Ko Y. G.: Properties and medical applications of polylactic acid: A review. Express Polymer Letters, 9, 435-455 (2015). https://doi.org/10.3144/expresspolymlett.2015.42

[4] Wang Y., Guo G., Chen H., Gao X., Fan R., Zhang D., Zhou L., Xiao L., Zhang X.: Preparation and characterization of polylactide/poly( $\varepsilon$-caprolactone)-poly(ethylene glycol)-poly( $\varepsilon$-caprolactone) hybrid fibers for potential application in bone tissue engineering. International Journal of Nanomedicine, 9, 1991-2003 (2014). https://doi.org/10.2147/IJN.S55318

[5] Gandini A.: Polymers from renewable resources: A challenge for the future of macromolecular materials. Macromolecules, 41, 9491-9504 (2008). https://doi.org/10.1021/ma801735u

[6] Vijayarajan S., Selke S. E., Matuana L. M.: Continuous blending approach in the manufacture of epoxidized soybean-plasticized poly(lactic acid) sheets and films. Macromolecular Materials and Engineering, 299, 622630 (2014).

https://doi.org/10.1002/mame.201300226

[7] Xiong Z., Yang Y., Feng J., Zhang X., Zhang C., Tang Z., Zhu J.: Preparation and characterization of poly(lactic acid)/starch composites toughened with epoxidized soybean oil. Carbohydrate Polymers, 92, 810-816 (2013). https://doi.org/10.1016/j.carbpol.2012.09.007

[8] Carbonell-Verdu A., Ferri J. M., Dominici F., Boronat T., Sanchez-Nacher L., Balart R., Torre L.: Manufacturing and compatibilization of PLA/PBAT binary blends by cottonseed oil-based derivatives. Express Polymer Letters, 12, 808-823 (2018).

https://doi.org/10.3144/expresspolymlett.2018.69

[9] Carbonell-Verdu A., Garcia-Garcia D., Dominici F., Torre L., Sanchez-Nacher L., Balart R.: PLA films with improved flexibility properties by using maleinized cottonseed oil. European Polymer Journal, 91, 248-259 (2017).

https://doi.org/10.1016/j.eurpolymj.2017.04.013

[10] Carbonell-Verdu A., Samper M. D., Garcia-Garcia D., Sanchez-Nacher L., Balart R.: Plasticization effect of epoxidized cottonseed oil (ECSO) on poly(lactic acid). Industrial Crops Products, 104, 278-286 (2017). https://doi.org/10.1016/j.indcrop. 2017.04.050

[11] Ruellan A., Guinault A., Sollogoub C., Chollet G., AitMada A., Ducruet V., Domenek S.: Industrial vegetable oil by-products increase the ductility of polylactide. Express Polymer Letters, 9, 1087-1103 (2015). https://doi.org/10.3144/expresspolymlett.2015.98

[12] Mauck S. C., Wang S., Ding W., Rohde B. J., Fortune C. K., Yang G., Ahn S-K., Robertson M. L.: Biorenewable tough blends of polylactide and acrylated epoxidized soybean oil compatibilized by a polylactide star polymer. Macromolecules, 49, 1605-1615 (2016). https://doi.org/10.1021/acs.macromol.5b02613 
[13] Robertson M. L., Chang K., Gramlich W. M., Hillmyer M. A.: Toughening of polylactide with polymerized soybean oil. Macromolecules, 43, 1807-1814 (2010). https://doi.org/10.1021/ma9022795

[14] Chen Y., Yuan D., Xu C.: Dynamically vulcanized biobased polylactide/natural rubber blend material with continuous cross-linked rubber phase. ACS Applied Materials and Interfaces, 6, 3811-3816 (2014). https://doi.org/10.1021/am5004766

[15] Liu W., Qiu J., Fei M-E., Qiu R., Sakai E.: Manufacturing of thermally remoldable blends from epoxidized soybean oil and poly(lactic acid) via dynamic crosslinking in a twin-screw extruder. Industrial and Engineering Chemistry Research, 57, 7516-7524 (2018). https://doi.org/10.1021/acs.iecr.8b01189

[16] Zhao T-H., Yuan W-Q., Li Y-D., Weng Y-X., Zeng J-B.: Relating chemical structure to toughness via morphology control in fully sustainable sebacic acid cured epoxidized soybean oil toughened polylactide blends. Macromolecules, 51, 2027-2037 (2018).

https://doi.org/10.1021/acs.macromol.8b00103

[17] Zhao T-H., He Y., Li Y-D., Wang M., Zeng J-B.: Dynamic vulcanization of castor oil in a polylactide matrix for toughening. RSC Advances, 6, 79542-79553 (2016). https://doi.org/10.1039/C6RA13631A

[18] He Y., Zhao T-H., Li Y-D., Wang M., Zeng J-B.: Toughening polylactide by dynamic vulcanization with castor oil and different types of diisocyanates. Polymer Testing, 59, 470-477 (2017).

https://doi.org/10.1016/j.polymertesting.2017.03.009

[19] Liu W., Qiu J., Zhu L., Fei M-E., Qiu R., Sakai E., Ito K., Song G., Tang G.: Tannic acid-induced crosslinking of epoxidized soybean oil for toughening poly(lactic acid) via dynamic vulcanization. Polymer, 148, 109 118 (2018). https://doi.org/10.1016/j.polymer.2018.06.021

[20] Qi M., Xu Y-J., Rao W-H., Luo X., Chen L., Wang Y-Z.: Epoxidized soybean oil cured with tannic acid for fully bio-based epoxy resin. RSC Advances, 8, 26948-26958 (2018).

https://doi.org/10.1039/C8RA03874K

[21] Qian S., Sheng K., Yu K., Xu L., Lopez C. A. F.: Improved properties of PLA biocomposites toughened with bamboo cellulose nanowhiskers through silane modification. Journal of Materials Science, 53, 10920 10932 (2018).

https://doi.org/10.1007/s10853-018-2377-2

[22] Graupner N., Albrecht K., Ziegmann G., Enzler H., Müssig J.: Influence of reprocessing on fibre length distribution, tensile strength and impact strength of injection moulded cellulose fibre-reinforced polylactide (PLA) composites. Express Polymer Letters, 10, 647663 (2016).

https://doi.org/10.3144/expresspolymlett.2016.59
[23] Sullivan E. M., Gerhardt R. A., Wang B., Kalaitzidou K.: Effect of compounding method and processing conditions on the electrical response of exfoliated graphite nanoplatelet/polylactic acid nanocomposite films. Journal of Materials Science, 51, 2980-2990 (2016). https://doi.org/10.1007/s10853-015-9609-5

[24] Piekarska K., Sowinski P., Piorkowska E., Haque M. M-U., Pracella M.: Structure and properties of hybrid PLA nanocomposites with inorganic nanofillers and cellulose fibers. Composites Part A: Applied Science and Manufacturing, 82, 34-41 (2016). https://doi.org/10.1016/j.compositesa.2015.11.019

[25] Luo Y., Cao Y., Guo G.: Effects of $\mathrm{TiO}_{2}$ nanoparticles on the photodegradation of poly(lactic acid). Journal of Applied Polymer Science, 135, 46509/1-46509/8 (2018). https://doi.org/10.1002/app.46509

[26] Rashmi B. J., Prashantha K., Lacrampe M-F., Krawczak P.: Toughening of poly(lactic acid) without sacrificing stiffness and strength by melt-blending with polyamide 11 and selective localization of halloysite nanotubes. Express Polymer Letters, 9, 721-735 (2015). https://doi.org/10.3144/expresspolymlett.2015.67

[27] Zhou S., Hrymak A. N., Kamal M. R.: Properties of microinjection-molded multi-walled carbon nanotubesfilled poly(lactic acid)/poly[(butylene succinate)-coadipate] blend nanocomposites. Journal of Materials Science, 53, 9013-9025 (2018). https://doi.org/10.1007/s10853-018-2193-8

[28] Mittal G., Dhand V., Rhee K. Y., Park S-J., Lee W. R.: A review on carbon nanotubes and graphene as fillers in reinforced polymer nanocomposites. Journal of Industrial and Engineering Chemistry, 21, 11-25 (2015). https://doi.org/10.1016/j.jiec.2014.03.022

[29] Wang L., Qiu J., Sakai E., Wei X.: The relationship between microstructure and mechanical properties of carbon nanotubes/polylactic acid nanocomposites prepared by twin-screw extrusion. Composites Part A: Applied Science and Manufacturing, 89, 18-25 (2016). https://doi.org/10.1016/j.compositesa.2015.12.016

[30] Brzeziński M., Biela T.: Polylactide nanocomposites with functionalized carbon nanotubes and their stereocomplexes: A focused review. Materials Letters, 121, 244-250 (2014).

https://doi.org/10.1016/j.matlet.2014.01.159

[31] Alam J., Alam M., Raja M., Abduljaleel Z., Dass L. A.: MWCNTs-reinforced epoxidized linseed oil plasticized polylactic acid nanocomposite and its electroactive shape memory behaviour. International Journal of Molecular Sciences, 15, 19924-19937 (2014).

https://doi.org/10.3390/ijms151119924

[32] Alam J., Khan A., Alam M., Mohan R.: Electroactive shape memory property of a Cu-decorated CNT dispersed PLA/ESO nanocomposite. Materials, 8, 63916400 (2015).

https://doi.org/10.3390/ma8095313 
[33] Yang J., Qi X., Zhang N., Huang T., Wang Y.: Carbon nanotubes toughened immiscible polymer blends. Composites Communications, 7, 51-64 (2018).

https://doi.org/10.1016/j.coco.2017.12.010

[34] Raja M., Ryu S. H., Shanmugharaj A.: Thermal, mechanical and electroactive shape memory properties of polyurethane (PU)/poly (lactic acid) (PLA)/CNT nanocomposites. European Polymer Journal, 49, 3492-3500 (2013).

https://doi.org/10.1016/j.eurpolymj.2013.08.009

[35] Shi Y-Y., Zhang W-B., Yang J-H., Huang T., Zhang N., Wang Y., Yuan G-P., Zhang C-L.: Super toughening of the poly(L-lactide)/thermoplastic polyurethane blends by carbon nanotubes. RSC Advances, 3, 26271-26282 (2013).

https://doi.org/10.1039/c3ra43253j

[36] Wu D., Zhang Y., Zhang M., Yu W.: Selective localization of multiwalled carbon nanotubes in poly ( $\varepsilon$-caprolactone)/polylactide blend. Biomacromolecules, 10, 417-424 (2009).

https://doi.org/10.1021/bm801183f

[37] Huang J., Mao C., Zhu Y., Jiang W., Yang X.: Control of carbon nanotubes at the interface of a co-continuous immiscible polymer blend to fabricate conductive composites with ultralow percolation thresholds. Carbon, 73, 267-274 (2014). https://doi.org/10.1016/j.carbon.2014.02.063

[38] Nasti G., Gentile G., Cerruti P., Carfagna C., Ambrogi V.: Double percolation of multiwalled carbon nanotubes in polystyrene/polylactic acid blends. Polymer, 99, 193-203 (2016).

https://doi.org/10.1016/j.polymer.2016.06.058

[39] Urquijo J., Aranburu N., Dagréou S., Guerrica-Echevarría G., Eguiazábal J.: CNT-induced morphology and its effect on properties in PLA/PBAT-based nanocomposites. European Polymer Journal, 93, 545-555 (2017). https://doi.org/10.1016/j.eurpolymj.2017.06.035

[40] Gao T., Li Y-Y., Bao R-Y., Liu Z-Y., Xie B-H., Yang MB., Yang W.: Tailoring co-continuous like morphology in blends with highly asymmetric composition by MWCNTs: Towards biodegradable high-performance electrical conductive poly(L-lactide)/poly(3-hydroxybutyrate-co-4-hydroxybutyrate) blends. Composites Science and Technology, 152, 111-119 (2017).

https://doi.org/10.1016/j.compscitech.2017.09.014

[41] Shi Y., Li Y., Xiang F., Huang T., Chen C., Peng Y., Wang Y.: Carbon nanotubes induced microstructure and mechanical properties changes in cocontinuous poly( L-lactide)/ethylene-co-vinyl acetate blends. Polymers for Advanced Technologies, 23, 783-790 (2012). https://doi.org/10.1002/pat.1959

[42] Wang X-F., He Z-Z., Yang J-H., Zhang N., Huang T., Wang Y., Zhou Z-W.: Super toughened immiscible poly (L-lactide)/poly(ethylene vinyl acetate) (PLLA/EVA) blend achieved by in situ cross-linking reaction and carbon nanotubes. Composites Part A: Applied Science and Manufacturing, 91, 105-116 (2016).

https://doi.org/10.1016/j.compositesa.2016.09.020
[43] Desa M. S. Z. M., Hassan A., Arsad A., Arjmandi R., Mohammad N. N. B.: Influence of rubber content on mechanical, thermal, and morphological behavior of natural rubber toughened poly(lactic acid)-multiwalled carbon nanotube nanocomposites. Journal of Applied Polymer Science, 133, 44344/1-44344/9 (2016). https://doi.org/10.1002/app.44344

[44] Wang Y-H., Xu X-L., Dai J., Yang J-H., Huang T., Zhang N., Wang Y., Zhou Z-W., Zhang J-H.: Super toughened immiscible polycarbonate/poly(L-lactide) blend achieved by simultaneous addition of compatibilizer and carbon nanotubes. RSC Advances, 4, 5919459203 (2014). https://doi.org/10.1039/C4RA11282B

[45] Liu Z., Bai H., Luo Y., Zhang Q., Fu Q.: Achieving a low electrical percolation threshold and superior mechanical performance in poly(L-lactide)/thermoplastic polyurethane/carbon nanotubes composites via tailoring phase morphology with the aid of stereocomplex crystallites. RSC Advances, 7, 11076-11084 (2017). https://doi.org/10.1039/C6RA27401C

[46] Wang L., Lee R. E., Wang G., Chu R. K., Zhao J., Park C. B.: Use of stereocomplex crystallites for fully-biobased microcellular low-density poly(lactic acid) foams for green packaging. Chemical Engineering Journal, 327, 1151-1162 (2017).

https://doi.org/10.1016/j.cej.2017.07.024

[47] Radjabian M., Kish M., Mohammadi N.: Structureproperty relationship for poly(lactic acid) (PLA) filaments: Physical, thermomechanical and shape memory characterization. Journal of Polymer Research, 19, 9870/1-9870/10 (2012).

https://doi.org/10.1007/s10965-012-9870-0

[48] Zhao S., Abu-Omar M. M.: Renewable epoxy networks derived from lignin-based monomers: Effect of crosslinking density. ACS Sustainable Chemistry and Engineering, 4, 6082-6089 (2016).

https://doi.org/10.1021/acssuschemeng.6b01446

[49] Arjmandi R., Hassan A., Haafiz M. K. M., Zakaria Z., Islam M. S.: Effect of hydrolysed cellulose nanowhiskers on properties of montmorillonite/polylactic acid nanocomposites. International Journal of Biological Macromolecules, 82, 998-1010 (2016). https://doi.org/10.1016/j.ijbiomac.2015.11.028

[50] Hu X., Li Y., Li M., Kang H., Zhang L.: Renewable and supertoughened polylactide-based composites: Morphology, interfacial compatibilization, and toughening mechanism. Industrial and Engineering Chemistry Research, 55, 9195-9204 (2016). https://doi.org/10.1021/acs.iecr.6b02159

[51] Liu H., Bai H., Bai D., Liu Z., Zhang Q., Fu Q.: Design of high-performance poly(L-lactide)/elastomer blends through anchoring carbon nanotubes at the interface with the aid of stereocomplex crystallization. Polymer, 108, 38-49 (2017). https://doi.org/10.1016/j.polymer.2016.11.034 